\title{
Community-based Monitoring Demonstrates Increasing Occurrences and Abundances of Pacific Salmon in the Canadian Arctic from 2000 to 2017
}

\author{
Karen M. Dunmall, Darcy G. McNicholl, and James D. Reist \\ Fisheries and Oceans Canada, 501 University Cr., Winnipeg, Manitoba, Canada, R3T 2N6
}

Keywords: Pacific salmon, Arctic, range extension, climate change, temperature, subsistence harvest

\section{Introduction}

Changing environmental conditions have precipitated northward distributional shifts for many marine ectotherms (Sunday et al. 2012). As salmon distributions are linked to species-specific thermal tolerances (Welch et al. 1998), warming trends have also been used to predict northward shifts in salmon species and their habitats (Welch et al. 1995; Kaeriyama 2008; Abdul-Aziz et al. 2011; Yoon et al. 2015). Indeed, Pacific salmon Oncorhynchus spp. appear to be responding to these warming trends as relatively high abundances of juvenile pink and chum salmon were caught in the Chukchi Sea in 2007 (Eisner et al. 2013), and immature chum salmon were found at higher latitudes in the Bering Sea in 2009 (Sato et al. 2012). Although Pacific salmon are not new to the Arctic (Stephenson 2006; Nielson et al. 2013), trends of increasing Pacific salmon harvests in subsistence fisheries in the Canadian Arctic are also apparent (Dunmall et al. 2013). Pacific salmon appear to be naturally accessing Arctic habitats as conditions become more favorable (Babaluk et al. 2000a; Grebmeier et al. 2006), which contributes to the perception of the Arctic as a conservation haven for salmon in a warming environment (Rand et al. 2012).

The Arctic, however, is vast, remote, and sparsely populated. It is exceedingly difficult, therefore, to detect and monitor widening geographic presence and increasing abundance trends of rare species in such an environment. Salmon, which are occasionally harvested as bycatch in subsistence fisheries across the Canadian Arctic, may be acting as effective indicators of climate warming by shifting distributions northward in response to environmental change (Dunmall et al. 2013; Dunmall 2018). By developing a community-based monitoring program, called Arctic Salmon, that responds to community-driven interest and questions about increasing salmon harvests, it is possible to document trends in salmon abundance in the Canadian Arctic. This information guides research to better understand the environmental factors influencing distributional shifts of marine species northward and can be used to assess the risks and opportunities associated with increasing salmon in the Canadian Arctic.

Here the objective is to summarize changes in salmon abundance, distribution and species composition in subsistence harvests in Canadian Arctic since previous reviews (Stephenson 2006; Nielson et al. 2013; Dunmall et al. 2013). This information also contributes to the establishment of community-based monitoring as an effective method to detect rare fish species across a vast and remote geographic area, and highlights the role of salmon as a sentinel useful to monitor a rapidly changing Arctic.

Methods

A Pacific Salmon Collection Program was established by Fisheries and Oceans Canada in 2000 to monitor increased harvests of Pacific salmon in subsistence fisheries in the Northwest Territories. This program was expanded as Arctic Salmon in 2011 and is now a community-based monitoring tool tracking distribution and relative abundance changes for Pacific salmon across the Canadian Arctic. Using this program, subsistence harvesters can voluntarily provide specimens of salmon to document trends in abundances and distributions for all species. For detailed methods see Dunmall et al. (2013) and Dunmall (2018).

Reports of Pacific salmon harvested from 2013 to 2017 and provided to Fisheries and Oceans Canada through Arctic Salmon are summarized by species and compared to previous reports of salmon from 2000 to 2012 (Dunmall et al. 2013). Note that salmon abundance data are preliminary for 2017. Species identification was verified from actual specimens using keys of morphological and meristic counts (e.g., Scott and Crossman 1973).

Results

Pacific salmon are increasing in abundance and in geographic distribution in the Canadian Arctic. The number of salmon reported, the number of species of salmon harvested, and the geographic area of subsistence fisheries documenting salmon harvests all increased from 2013 to 2017.

Chum salmon (Oncorhynchus keta) 
Chum salmon is consistently the most abundant Pacific salmon species harvested across the Canadian Arctic. It is also the only species with a long history and traditional knowledge of harvesting in the Mackenzie River (Dunmall et al. 2013). Moreover, at present chum salmon is the only salmon species that appears to have reproducing populations in the western Arctic (Dunmall 2018). Trends in chum salmon harvests include consistent low-level harvests in subsistence fisheries along the Mackenzie River, and occasional years of higher level harvests, called "exceptional years" (Fig. 1; Dunmall 2018). Two exceptional years occurred in 2016 and 2017, which contribute to an increasing trend in the frequency of these exceptional years. Also, the number of salmon that may be present during these exceptional years also appears to be increasing as the number of chum salmon provided during each of 2016 and 2017 doubled those provided in previous exceptional years, whereas numbers of chum salmon provided during the low-level harvest years remained consistent (Fig. 1).

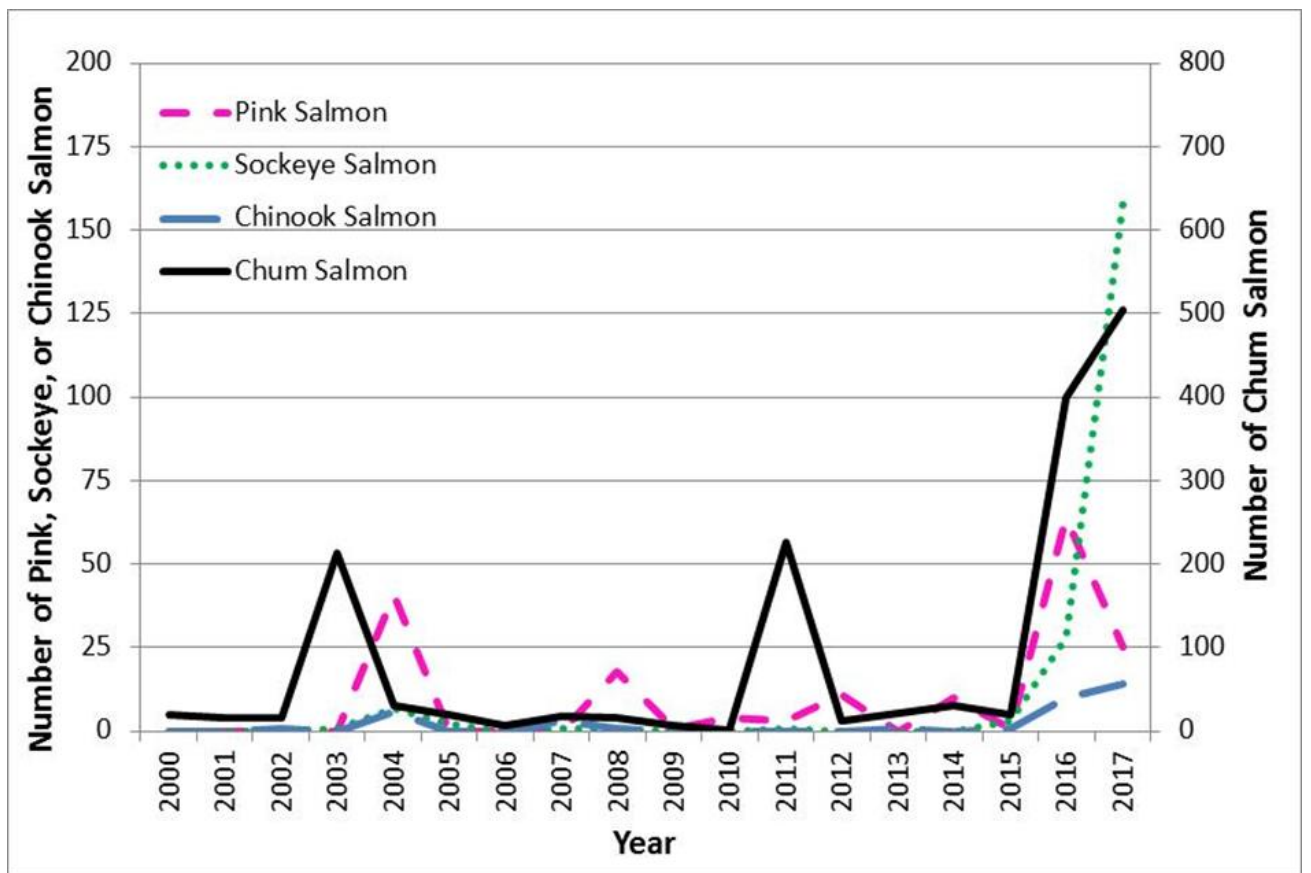

Fig. 1. The number of each species of Pacific salmon traded in to the Arctic Salmon community-based monitoring program from harvesters across the Canadian Arctic from 2000-2017. Only one coho salmon was reported during this period (in 2011), thus it is not included.

Pink salmon (Oncorhynchus gorbuscha)

Higher pink salmon harvests occur in even-numbered years compared to odd-numbered years (Fig. 1). The number of pink salmon reported during both even and odd years, however, is increasing. Also, the geographic distribution of pink salmon harvests is increasing as they have now been reported in new locations, including Kugluktuk, Nunavut, and upstream in the Mackenzie River to Ft. Good Hope, Northwest Territories.

\section{Sockeye salmon (Oncorhynchus nerka)}

Sockeye salmon have experienced a rapid increase in reported harvests in the western Canadian Arctic in 2016 and 2017. Reported harvests increased from less than 10 per year from 2000 to 2015 to over 150 sockeye salmon reported in 2017 (Fig. 1). While several communities along the Mackenzie River reported higher sockeye harvests, the change was most pronounced in communities surrounding the Beaufort Sea. The geographic extent of sockeye salmon harvests also expanded eastward to now also include Cambridge Bay, Nunavut where two sockeye salmon were reported harvested in 2016 and one was reported in 2017.

\section{Chinook (Oncorhynchus tshawytscha) and Coho salmon (Oncorhynchus kisutch)}

The number of Chinook salmon reported increased in 2016 and 2017 compared to previous years, although the change was not as pronounced as it was for the other species of Pacific salmon (Fig. 1). Reported harvests increased from less than five per year from 2000 to 2015 to 10 in 2016 and 14 in 2017. No coho salmon were reported harvested in the Canadian Arctic from 2013 to 2017. 


\section{Conclusion}

All species of Pacific salmon, with the exception of coho salmon, have rapidly increased in abundance and have expanded in geographic presence in the western Canadian Arctic since 2013, although the change is most pronounced in 2016 and 2017. While this increase may be due to an increase in reporting of harvested salmon by community harvesters, rather than an actual increase in the abundance of salmon themselves, the increase is consistent across almost all the communities in the western Canadian Arctic and for multiple species of salmon. Also, local knowledge suggests that more salmon have been present in the western Canadian Arctic in recent years. Therefore, the trends suggest that the occurrences and likely also the abundances of chum, pink, sockeye, and Chinook salmon are increasing in the Canadian Arctic, and at rates of increase not previously recorded.

The Arctic Salmon community-based monitoring program has also expanded in recent years. The geographic extent of the Arctic Salmon project now includes communities in Nunavut to facilitate the detection of Pacific salmon and Atlantic salmon in subsistence fisheries across the Canadian Arctic. The Arctic Salmon program has also shifted from monitoring salmon to monitoring the harvest of all "unusual fish" across the Canadian Arctic. These "unusual fish" include reports of all Pacific salmon species, Atlantic salmon, and also fish species that are native to the Arctic but are now found outside known distributions. This expansion is evidence of both the success of Arctic Salmon as a monitoring program among communities in the Canadian Arctic, and of the relevance of a community-based program for monitoring rare and potentially colonizing species across a vast and remote area.

Acknowledgments - We thank all participants of the Arctic Salmon community-based monitoring program, including harvesters, community organizations, government offices, and individuals, for providing samples and assisting in coordinating collections from across the Canadian Arctic. This research is only possible because of their contributions. We thank all organizations who provided funding support. We also thank the Alaska Department of Fish and Game Gene Conservation Laboratory for their efforts to confirm species identification for the sockeye salmon harvested in Nunavut. For more information on Arctic Salmon, please visit www.facebook.com/arcticsalmon.

\section{REFERENCES}

Abdul-Aziz, O.I., N.J. Mantua, and K.W. Myers. 2011. Potential climate change impacts on thermal habitats of Pacific salmon (Oncorhynchus spp.) in the North Pacific Ocean and adjacent seas. Can. J. Fish. Aquat. Sci. 68: 1660-1680. doi: 10.1139/f2011-079

Babaluk, J.A., J.D. Reist, J.D. Johnson, and L. Johnson. 2000. First records of sockeye (Oncorhynchus nerka) and pink salmon (O. gorbuscha) from Banks Island and other records of Pacific salmon in Northwest Territories, Canada. Arctic 53: 161-164. doi: 10.14430/arctic846

Dunmall, K.M. 2018. Pacific salmon in the Canadian Arctic: Indicators of change. Ph.D. thesis, Univ. Manitoba, Winnipeg. 227 pp.

Dunmall, K.M., J.D. Reist, E.C. Carmack, J.A. Babaluk, M.P. Heide-Jørgensen, and M.F. Docker. 2013. Pacific salmon in the Arctic: Harbingers of recent great changes. In Responses of Arctic marine ecosystems to climate change. Edited by F.J. Mueter, D.M.S. Dickson, H.P. Huntington, J.R. Irvine, E.A. Logerwell, S.A. MacLean, L.T. Quakenbush, and C. Rosa. Alaska Sea Grant, University of Alaska Fairbanks. pp. 141-163. doi: 10.4027/ramecc.2013.07

Eisner, L., N. Hillgruber, E. Martinson, and J. Maselko. 2013. Pelagic fish and zooplankton species assemblages in relation to water mass characteristics in the northern Bering and southeast Chukchi seas. Polar Biol. 36: 87113. doi: 10.1007/s00300-012-1241-0

Grebmeier, J.M., J.E. Overland, S.E. Moore, E.V. Farley, E.C. Carmack, L.W. Cooper, K.E. Frey, J.H. Helle, F.A. McLaughlin, and S.L. McNut. 2006. A major ecosystem shift in the northern Bering Sea. Science 311: 14611463. doi:10.1126/science. 1121365 .

Kaeriyama, M. 2008. Ecosystem-based sustainable conservation and management of Pacific salmon. In Fisheries for global welfare and environment. Edited by K. Tsukamoto, T. Kawamura, T. Takeuchi, T.D. Beard, Jr., and M.J. Kaiser. Proceedings of 5th World Fisheries Congress. TerraPub., Japan. pp. 371-380.

Nielsen, J.L., G.T. Ruggerone, and C.E. Zimmerman. 2013. Adaptive strategies and life history characteristics in a warming climate: Salmon in the Arctic? Environ. Biol. Fish. 96: 1187-1226. doi:10.1007/s10641-012-0082-6. 
Rand, P.S, M. Goslin, M.R. Gross, J.R. Irvine, X. Augerot, et al. 2012. Global assessment of extinction risk to populations of sockeye salmon Oncorhynchus nerka. PLoS ONE 7(4): e34065. doi:10.1371/journal.pone.0034065

Sato, S., M. Kato, K. Morita, and S. Urawa. 2012. Stock-specific summertime distribution of immature chum salmon in the Bering Sea as inferred from SNP markers. N. Pac. Anadr. Fish Comm. Tech. Rep. 8: 50-51. (Available at http://www.npafc.org)

Scott, W.B., and E.J. Crossman. 1973. Freshwater fishes of Canada. Bull. Fish. Res. Board Can. 184. 966 pp.

Stephenson, S.A. 2006. A review of the occurrence of Pacific salmon (Oncorhynchus spp.) in the Canadian Western Arctic. Arctic 59(1): 37-46.

Sunday, J.M., A.E. Bates, and N.K. Dulvy. 2012. Thermal tolerance and the global redistribution of animals. Nature Clim. Change. 2: 686-690. doi: 10.1038/nclimate1539

Welch, D.W., A.E. Chigirinsky, and Y. Ishida. 1995. Upper thermal limits on the oceanic distribution of Pacific salmon (Oncorhynchus spp.) in the spring. Can. J. Fish. Aquat. Sci. 52: 489-503. doi: 10.1139/f95-050

Welch, D.W., Y. Ishida, and K. Nagasawa. 1998. Thermal limits and ocean migrations of sockeye salmon (Oncorhynchus nerka): long-term consequences of global warming. Can. J. Fish. Aquat. Sci. 55: 937-948. doi: $10.1139 / \mathrm{f} 98-023$

Yoon, S., E. Watanabe, U. Hiromichi, and M.J. Kishi. 2015. Potential habitat for chum salmon (Oncorhynchus keta) in the Western Arctic based on a bioenergetics model coupled with a three-dimensional lower trophic ecosystem model. Prog. Oceanogr. 131: 146-158. doi: 10.1016/j.pocean.2014.12.009 